\title{
Shear-induced ringwoodite formation in the Martian shergottite Dar al Gani 670
}

\author{
Ansgar Greshake ${ }^{\mathrm{a}, *}$, Jörg Fritz $^{\mathrm{a}}$, Ute Böttger ${ }^{\mathrm{b}}$, Daniel Goran ${ }^{\mathrm{c}}$ \\ ${ }^{a}$ Museum für Naturkunde, Leibniz-Institut für Evolutions- und Biodiversitätsforschung, Invalidenstraße 43, 10115 Berlin, Germany \\ ${ }^{\mathrm{b}}$ German Aerospace Center DLR e.V., Institute of Planetary Research, Rutherfordstraße 2, 12489 Berlin, Germany \\ ' Bruker Nano GmbH, Schwarzschildstraße 12, 12489 Berlin, Germany
}

\section{A R T I C L E I N F O}

\section{Article history:}

Received 27 September 2012

Received in revised form 25 April 2013

Accepted 3 June 2013

Editor: L. Stixrude

Available online 28 June 2013

\section{Keywords:}

Martian meteorites

Dar al Gani 670

high-pressure phases

ringwoodite

shearing

shock metamorphism

\begin{abstract}
A B S T R A C T
Shock-produced melt veins in the Martian shergottite Dar al Gani 670 crosscut large olivine crystals. The upper part of one of these crystals appears to be sheared off and displaced along the shock vein. From the olivine-vein interface small lamellae of ringwoodite grow into the host crystal. The $\leq 1-3 \mu \mathrm{m}$ wide and up to $20 \mu \mathrm{m}$ long lamellae consist of small bands and blocks and are orientated along specific crystallographic orientations. Texture and composition, i.e., more Fe-rich than the host olivine, indicate that lamellae formed via incoherent diffusion-controlled growth. It is suggested that a combination of high particle velocities and shock-induced defects lead to enhanced diffusion rates. In addition, shearing caused grain size reduction allowing rapid Fe-Mg interchange and induced lattice defects serving as nucleation sites for ringwoodite. Crystallographic orientation of ringwoodite lamellae indicates that during shock deformation the $[001]\{h k 0\}$ slip system was activated in olivine. Natural high-pressure phases in Martian meteorite allow to constrain phase transitions taking place in the inaccessible Earth's mantle. High-pressure shear instabilities of olivine at subduction zones in 400-700 km depth are considered being responsible for deep earthquakes. At such $p-T$-conditions, breakdown of olivine results in formation of ringwoodite filled micro-anticracks which interact with each other finally leading to catastrophic shear failure. Our results strongly suggest that shearing itself contributes to a runaway process of enhanced ringwoodite formation and, thus, reinforces catastrophic material failure that may result in deep earthquakes.
\end{abstract}

(c) 2013 Elsevier B.V. All rights reserved.

\section{Introduction}

Olivine is the most abundant mineral in the Earth's upper mantle. At greater depth and increasing pressures and temperatures, i.e., in the transition zone which separates the upper from the lower mantle, it transforms first into wadsleyite ( $\beta$-olivine) and then into the spinel-structured ringwoodite ( $\gamma$-olivine). Globally observed seismic discontinuities are attributed to these phase transformations, i.e., at $410 \mathrm{~km}$ olivine is converted to wadsleyite which within the transition zone at $\sim 525 \mathrm{~km}$ transforms to ringwoodite. Finally, olivine dissociates into ( $\mathrm{Mg}$,Fe) $\mathrm{SiO}_{3}$-perovskite and magnesiowüstite. While in terrestrial rocks neither wadsleyite nor ringwoodite has been found so far, ringwoodite was discovered more than $40 \mathrm{yr}$ ago in the Tenham L6 chondrite (Binns et al., 1969). Meanwhile ringwoodite and the high-pressure phases of various other minerals have been identified in many heavily shocked ordinary chondrites, in very few carbonaceous

\footnotetext{
* Corresponding author. Tel.: +49 302093 8858; fax: +49 3020938868 .

E-mail address: ansgar.greshake@mfn-berlin.de (A. Greshake).
}

chondrites, and also in some lunar and Martian meteorites (e.g., Beck et al., 2004; Sharp and DeCarli, 2006 and references therein; Fritz and Greshake, 2009; Weisberg and Kimura, 2010; Zhang et al., 2010; Miyahara et al., 2011; Ohtani et al., 2011; Baziotis et al., 2013; Walton, 2013). The high-pressure polymorphs are generally found within or directly adjacent to thin, on average $100-500 \mu \mathrm{m}$ wide shock-melt veins. In and near the shock veins ringwoodite occurs as polycrystalline aggregates composed of numerous $100 \mathrm{~nm}$ to several $\mu \mathrm{m}$ sized crystallites all showing the same chemical composition as the neighbored olivine. This suggests that ringwoodite formed via an interface, rather than diffusion-controlled, solid-state mechanism during shock compression (e.g., Chen et al., 1996; Sharp and DeCarli, 2006). Furthermore, the homogeneous distributions and random orientation of the crystallites argue against heterogeneous nucleation on grain boundaries and favor homogeneous intracrystalline nucleation of ringwoodite throughout the olivine (e.g., Sharp and DeCarli, 2006).

Rare exceptions from this occurrence constitute ringwoodite/ wadsleyite composite grains found in chondrules entrained in shock melt veins (Miyahara et al., 2008) and those found in small $\sim 400 \mu \mathrm{m}$ sized shock melt pockets of the Martian dunite 
Chassigny (Fritz and Greshake, 2009). Their compositional zoning, i.e., Mg-rich core and more Fe-rich rim, evidences formation by fractional crystallization from a melt (Miyahara et al., 2008; Fritz and Greshake, 2009).

More recently lamellar ringwoodite was described from partially transformed olivine grains within and around shock veins in L6 chondrites (Ohtani et al., 2004; Chen et al., 2004, 2006, 2007; Beck et al., 2005; Xie and Sharp, 2007; Miyahara et al., 2010) and in lithology A of the Martian meteorite Elephant Moraine (EET) A79001 (Walton, 2013). The mostly discontinuous lamellae are generally only a few micrometers wide, are orientated along distinct crystallographic orientations, and, according to transmission electron microscopy (TEM) studies, predominantly consist of tiny, sub- $\mu \mathrm{m}$ sized randomly orientated ringwoodite crystallites (Xie and Sharp, 2007; Miyahara et al., 2010). All these observations are in favor of an incoherent (i.e., strong lattice misfit at the interface plane between ringwoodite and host olivine) transformation process. However, in one case, single ringwoodite lamellae were identified being composed of very thin ringwoodite platelets which depict coherent crystallographic orientations with the parent olivine (i.e., perfect lattice match at the olivine-ringwoodite interface, $(100)_{\mathrm{ol}} / /\{111\}_{\mathrm{rw}}$ ) suggesting coherent formation (Miyahara et al., 2010). Compositionally, lamellae with identical composition as the host olivine as well as lamellae displaying chemical zoning have been observed proving that both interface- and diffusioncontrolled processes may produce lamellar shaped ringwoodite. Summarizing, the intracrystalline formation of lamellar ringwoodite is so far attributed to either shear-related coherent growth (Chen et al., 2004), fracture-related incoherent growth (Chen et al., 2006, 2007), coherent and subsequent incoherent growth (Miyahara et al. 2010) or heterogeneous nucleation along specific planes in olivine (Xie and Sharp, 2007).

Shocked meteorites showing shear-stress related intracrystalline transformation of olivine to ringwoodite may provide the only available natural samples to study the processes operating in lithospheric slabs subducting into the Earth's mantle. Here we present the finding of ringwoodite lamellae in sheared olivine of the Martian basalt Dar al Gani 670 (Greshake et al., 2011) shedding new light on shear-stress triggered formation of olivine highpressure polymorphs.

\section{Samples and methods}

A doubly polished thin section of Dar al Gani 670 (hereafter DaG 670) (Fig. 1) was studied using optical microscopy, backscattered electron imaging (BSE), X-ray elemental mapping,
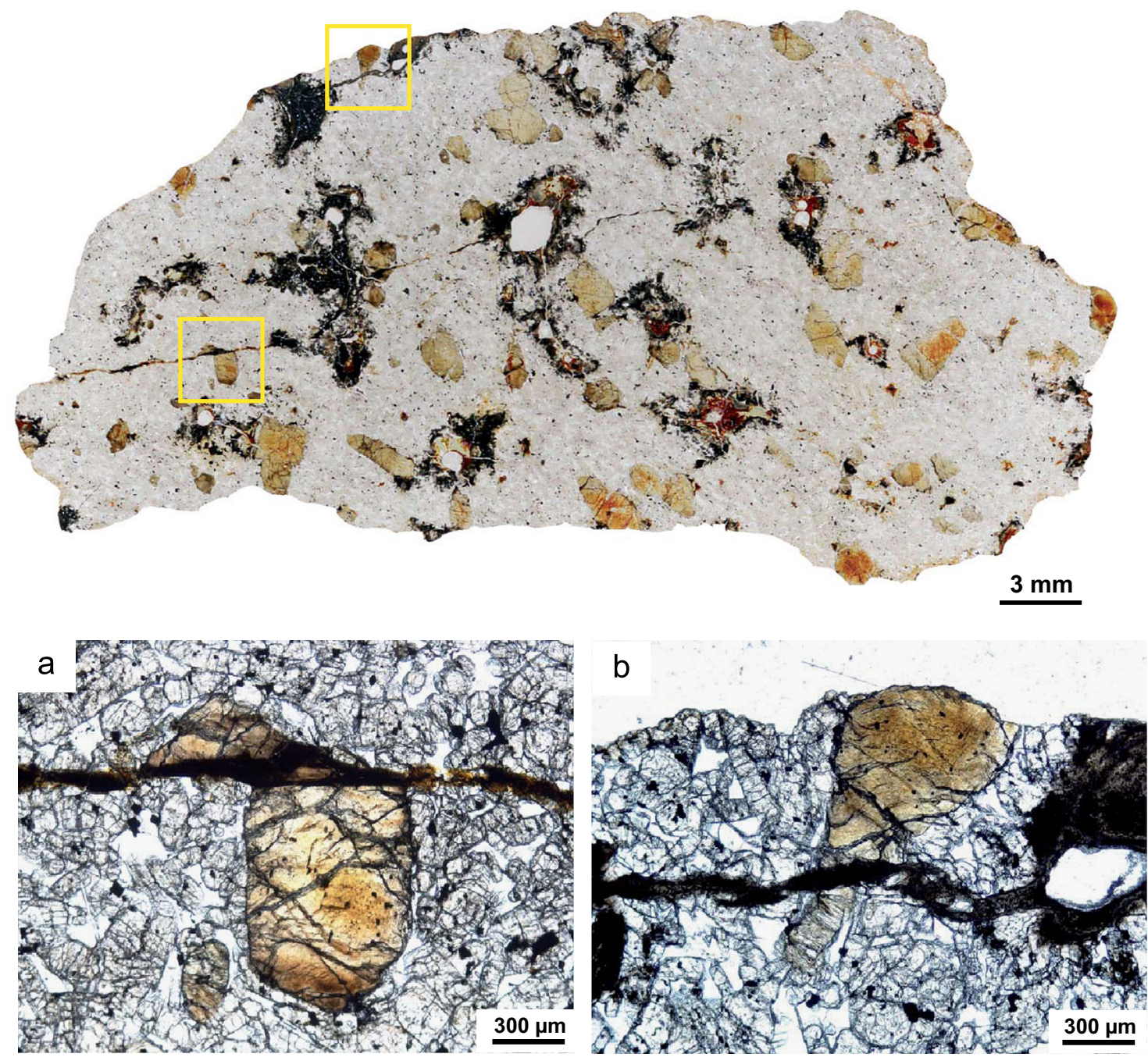

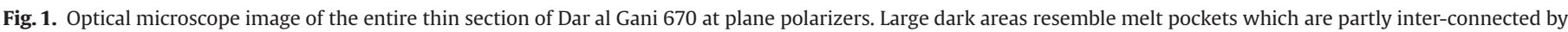

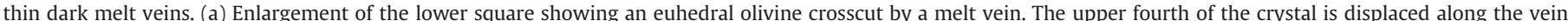
(plane polarizers). (b) Enlargement of the upper square showing an olivine cut by a melt vein without any observable displacement (plane polarizers). 
electron microprobe analysis, Raman spectroscopy, and electron backscatter diffraction (EBSD).

BSE images, quantitative mineral analyses, and X-ray elemental maps were obtained with a Jeol JXA 8500F field emission electron microprobe equipped with five wave lengths dispersive X-ray (WDX) spectrometer using a $10-15 \mathrm{kV}$ accelerating voltage, a $15 \mathrm{nA}$ beam current, and $1-3 \mu \mathrm{m}$ beam size. Suitable mineral standards including anorthoclase, basaltic glass, chromite, chromium augite, diopside, ilmenite, microcline, and plagioclase, all certified by the United States National Museum as reference samples for electron microprobe analysis (Jarosewich et al., 1980) were applied to calculate mineral and melt compositions.

Raman spectroscopy, comprising mapping and recording of single spectra, was carried out using a confocal Raman microscope WITec alpha 300R system operating with an Nd:YAG laser of $532 \mathrm{~nm}$ wavelengths. The sample excitation and Raman scatter collection was performed using a $100 \times$ objective on the Raman microscope. The laser power on the sample corresponded to $8 \mathrm{~mW}$ and the spot size in focus on the sample was $\sim 1.5 \mu \mathrm{m}$. All spectra were processed with the WITec Project Data Evaluation Software.

Electron backscatter diffraction (EBSD) was carried out using a QUANTAX CrystAlign system including the Bruker $e^{-}$Flash $^{1000}$ EBSD detector attached to a ZEISS Supra 55 VP field emission scanning electron microscope. For EBSD the thin section was mechanically polished with a $1 \mu \mathrm{m}$ diamond suspension followed by final polishing with colloidal silica to avoid the formation of surface relief and to remove the surface deformation layer.

DaG 670 was recovered in 1999 in the Dar al Gani region, Libyan Sahara as a single rock broken up into three adjoining fragments totaling $1619 \mathrm{~g}$ (Folco and Franchi, 2000). The meteorite is part of a strewn field in which so far eight independent fragments have been found (Meyer, 2013). According to their very similar mineralogy, chemical composition, degree of shock metamorphism, and exposure ages, these fragments are considered being paired, i.e., they represent pieces of a single meteoroid that disrupted during atmospheric entry. DaG 670 is an olivine-phyric shergottite and mainly consists of mm-sized olivine crystals set into a fine-grained basaltic groundmass of dominantly pigeonite and maskelynized plagioclase (Folco and Franchi, 2000 and also this study). Olivine generally shows compositional zoning from a $\mathrm{Mg}$-rich core to a more Fe-rich rim and frequently contains inclusions of chromite, symplectites, and solidified trapped melt. The meteorite is severely weathered containing abundant phyllosilicates and $\sim 2$ vol\% calcite typically filling fractures (Folco and Franchi, 2000). DaG 670 is heavily affected by shock metamorphism. Shock effects include planar and irregular fractures, strong mosaicism, and planar deformation features in olivine, intense fracturing and polysynthetic twinning in pyroxene, maskelynitized plagioclase as well as abundant shock-melt veins and pockets. According to the refractive index of maskelynite the paired meteorite Dar al Gani 476 (hereafter DaG 476), experienced an equilibrium shock pressure of $40-45 \mathrm{GPa}$ (Fritz et al., 2005). This value can be adopted for DaG 670 .

\section{Results}

Inspection of the $\sim 3.1 \times 1.6 \mathrm{~cm}^{2}$ measuring thin section of DaG 670 by optical microscopy revealed the presence of several $\mathrm{cm}$ sized melt pockets interconnected by melt veins (Fig. 1). These veins extend over several $\mathrm{cm}$ and sometimes crosscut large olivine crystals. In a remarkable case an olivine cut by a melt vein appears to be sheared along the vein while in another case no displacement is observed (Fig. 1).
Table 1

Representative analyses of non-sheared olivine, neighbored pyroxene, pyroxene in melt vein, and melt vein (see Figs. 1 and 2).

\begin{tabular}{lllllll}
\hline & Olivine & Pyroxene & $\begin{array}{l}\text { Pyroxene in melt } \\
\text { vein }\end{array}$ & $\begin{array}{l}\text { Melt } \\
\text { vein }\end{array}$ & $\begin{array}{l}\text { Melt } \\
\text { vein }\end{array}$ & $\begin{array}{l}\text { Melt } \\
\text { vein }\end{array}$ \\
\hline $\mathrm{SiO}_{2}$ & 36.42 & 52.91 & 53.02 & 48.46 & 49.03 & 48.9 \\
$\mathrm{TiO}_{2}$ & b.d. & 0.12 & 0.65 & 0.79 & 0.71 & 0.79 \\
$\mathrm{Al}_{2} \mathrm{O}_{3}$ & b.d. & 1.06 & 1.55 & 2.5 & 3.02 & 2.49 \\
$\mathrm{Cr}_{2} \mathrm{O}_{3}$ & 0.06 & 0.5 & 0.46 & 0.83 & 0.97 & 0.88 \\
$\mathrm{FeO}$ & 31.51 & 16.84 & 17.06 & 19.26 & 19.28 & 18.71 \\
$\mathrm{MnO}$ & 0.55 & 0.53 & 0.58 & 0.52 & 0.55 & 0.48 \\
$\mathrm{MgO}$ & 30.63 & 22.46 & 22.16 & 18.65 & 19.19 & 19.51 \\
$\mathrm{NiO}$ & n.a. & b.d. & n.a. & 0.14 & b.d. & 0.06 \\
$\mathrm{CaO}$ & 0.31 & 4.62 & 4.86 & 6.51 & 6.35 & 6.16 \\
$\mathrm{Na} \mathrm{O}_{2} \mathrm{O}$ & 0.03 & 0.08 & 0.16 & 0.16 & 0.16 & 0.1 \\
$\mathrm{~K} 2 \mathrm{O}$ & b.d. & b.d. & b.d. & b.d. & b.d. & b.d. \\
$\mathrm{P}_{2} \mathrm{O}_{5}$ & n.a. & 0.04 & n.a. & 0.71 & 0.54 & 0.65 \\
$\mathrm{~S}$ & n.a. & b.d. & n.a. & 0.67 & 0.31 & 0.23 \\
$\mathrm{Total}$ & 99.51 & 99.16 & 100.5 & 99.20 & 100.11 & 98.96 \\
$\mathrm{Formula}$ & & & & & & \\
$\mathrm{O}$ & 24 & 24 & 24 & & & \\
$\mathrm{Si}$ & 5.996 & 7.853 & 7.785 & & & \\
$\mathrm{Ti}$ & - & 0.013 & 0.072 & & & \\
$\mathrm{Al}$ & - & 0.185 & 0.268 & & & \\
$\mathrm{Cr}$ & 0.007 & 0.059 & 0.053 & & & \\
$\mathrm{Fe}$ & 4.338 & 2.090 & 2.095 & & & \\
$\mathrm{Mn}$ & 0.077 & 0.067 & 0.072 & & & \\
$\mathrm{Mg}$ & 7.518 & 4.970 & 4.851 & & & \\
$\mathrm{Ni}$ & - & - & - & & & \\
$\mathrm{Ca}$ & 0.055 & 0.735 & 0.764 & & & \\
$\mathrm{Na}$ & 0.008 & 0.023 & 0.045 & & & \\
$\mathrm{~K}$ & - & - & - & & & \\
$\mathrm{P}$ & - & 0.005 & - & & & \\
$\mathrm{Total}$ & 17.999 & 16.000 & 16.005 & & & \\
$\mathrm{Fa} / \mathrm{Fs}$ & 36.6 & 26.8 & 27.2 & & & \\
$\mathrm{Wo}$ & & 9.4 & 9.9 & & & \\
\hline $\mathrm{Da}$ & & & & & \\
\end{tabular}

Data in wt\%; b.d.: below detection limit; n.a.: not analyzed.

\subsection{Non-sheared olivine}

An $\sim 1.3 \mathrm{~mm}$ sized anhedral olivine crystal $\left(\mathrm{Fa}_{36.6}\right.$; Table 1$)$ is found to be crosscut by a 70-90 $\mu \mathrm{m}$ thick melt vein interconnecting two shock melt pockets. The vein cuts through the relatively narrow, $\sim 400 \mu \mathrm{m}$ wide tip of the crystal without any observable displacement between the upper and lower part of the olivine (Figs. 1 and 2). The melt vein-olivine interface is characterized by ragged outlines indicating no or only minor melting of the olivine (Fig. 2b). In contrast, pyroxene cut by the vein displays smooth outlines and partial dissolving (Fig. 2c). The vein is composed of an almost featureless solidified melt with high porosity and few embedded Fe-sulfide and -oxide droplets (Fig. 2d); entrained mineral fragments are completely absent. Although a typical quenched margin is not observed, a weak thermal gradient within the vein might be discernible with first, $\sim 1 \mu \mathrm{m}$ sized, Mg-rich pyroxene grains $\left(\mathrm{Fs}_{27.2} \mathrm{Wo}_{9.9}\right)$ crystallizing from the melt preferably close to the relatively cold vein-olivine contact (Fig. 2c; Table 1). X-ray elemental mapping, line profiles across olivine and vein as well as single defocused beam analyses reveal strongly enhanced $\mathrm{Si} /(\mathrm{Fe}+\mathrm{Mg})$-ratios relative to olivine as well as high $\mathrm{Al}$, Ca, Ti, P, and S concentrations (Table 1). High-pressure phases of olivine, or of other minerals, are neither observed within nor near the vein.

\subsection{Sheared olivine}

A nearly $1.3 \mathrm{~mm}$ sized, compositionally zoned (core: Fa 28.6, rim: $\mathrm{Fa}_{40.4}$; Table 2), almost euhedral olivine grain was found to be sheared along a shock-melt vein cutting through the crystal (Figs. 1 and 3; Table 2). The approximately upper fourth of the 

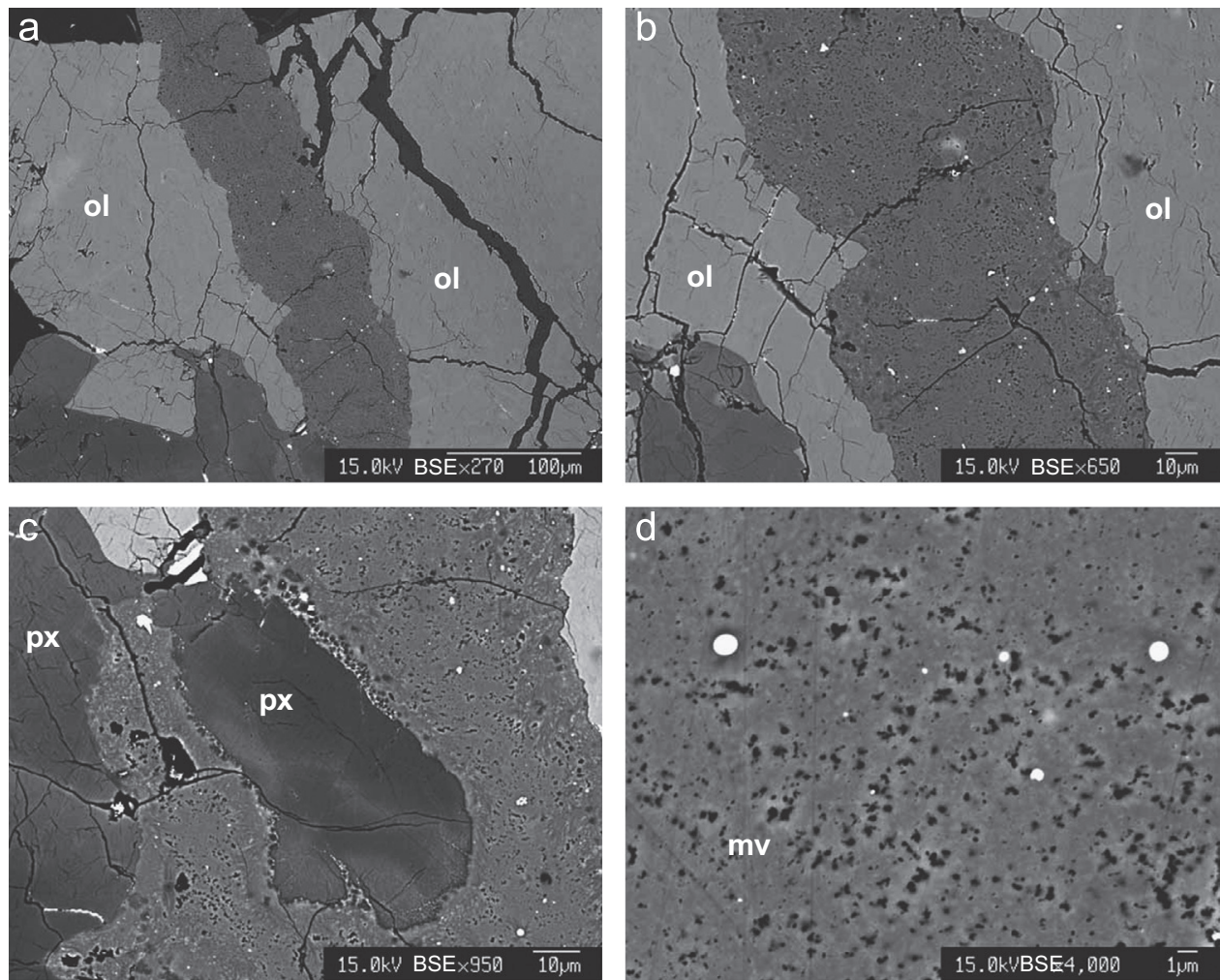

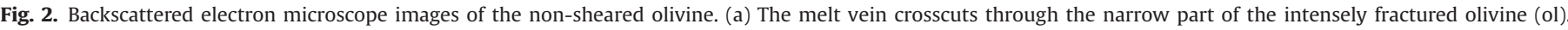

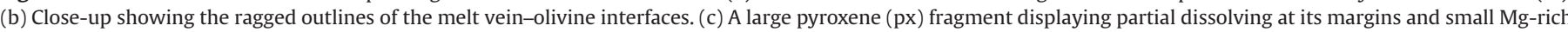
pyroxenes crystallizing from the melt. (d) The solidified melt in the vein (mv) is highly porous and rarely contains tiny Fe-sulfide and -oxide droplets.

Table 2

Representative analyses of the sheared olivine and different regions in the melt vein (see Figs. 1, 3, and 4)

\begin{tabular}{|c|c|c|c|c|c|c|}
\hline & $\begin{array}{l}\text { Olivine } \\
\text { core }\end{array}$ & $\begin{array}{l}\text { Olivine } \\
\text { rim }\end{array}$ & $\begin{array}{l}\text { Mg-rich } \\
\text { zone at } \\
\text { vein }\end{array}$ & $\begin{array}{l}\text { Quenched } \\
\text { margin }\end{array}$ & $\begin{array}{l}\text { Central part } \\
\text { of melt vein }\end{array}$ & $\begin{array}{l}\text { Central part } \\
\text { of melt vein }\end{array}$ \\
\hline $\mathrm{SiO}_{2}$ & 37.43 & 35.69 & 36.04 & 36.43 & 41.47 & 42.4 \\
\hline $\mathrm{TiO}_{2}$ & b.d. & b.d. & b.d. & 0.61 & 1.63 & 1.98 \\
\hline $\mathrm{Al}_{2} \mathrm{O}_{3}$ & 0.04 & b.d. & 0.08 & 0.66 & 2.21 & 2.17 \\
\hline $\mathrm{Cr}_{2} \mathrm{O}_{3}$ & 0.1 & 0.05 & 0.07 & 0.31 & 0.82 & 0.84 \\
\hline $\mathrm{FeO}$ & 25.5 & 34.36 & 29.58 & 32.69 & 25.3 & 24.38 \\
\hline $\mathrm{MnO}$ & 0.43 & 0.65 & 0.55 & 0.63 & 0.59 & 0.51 \\
\hline $\mathrm{MgO}$ & 35.71 & 28.48 & 32.02 & 25.82 & 22.55 & 22.34 \\
\hline $\mathrm{NiO}$ & n.a. & n.a. & n.a. & 0.03 & 0.06 & 0.1 \\
\hline $\mathrm{CaO}$ & 0.34 & 0.3 & 0.42 & 1.7 & 3.31 & 3.88 \\
\hline $\mathrm{Na}_{2} \mathrm{O}$ & b.d. & b.d. & 0.04 & b.d. & 0.18 & 0.16 \\
\hline $\mathrm{K}_{2} \mathrm{O}$ & b.d. & b.d. & b.d. & b.d. & b.d. & b.d. \\
\hline $\mathrm{P}_{2} \mathrm{O}_{5}$ & n.a. & n.a. & n.a. & 0.25 & 0.36 & 0.3 \\
\hline $\mathrm{S}$ & n.a. & n.a. & n.a. & 0.19 & 0.75 & 0.82 \\
\hline Total & 99.55 & 99.53 & 98.8 & 99.32 & 99.23 & 99.88 \\
\hline \multicolumn{7}{|c|}{ Formula } \\
\hline $\mathrm{O}$ & 24 & 24 & & & & \\
\hline $\mathrm{Si}$ & 5.975 & 5.966 & & & & \\
\hline $\mathrm{Ti}$ & - & - & & & & \\
\hline $\mathrm{Al}$ & 0.008 & - & & & & \\
\hline $\mathrm{Cr}$ & 0.012 & 0.006 & & & & \\
\hline $\mathrm{Fe}$ & 3.405 & 4.804 & & & & \\
\hline Mn & 0.058 & 0.092 & & & & \\
\hline $\mathrm{Mg}$ & 8.496 & 7.098 & & & & \\
\hline $\mathrm{Ni}$ & - & - & & & & \\
\hline $\mathrm{Ca}$ & 0.058 & 0.053 & & & & \\
\hline $\mathrm{Na}$ & - & - & & & & \\
\hline $\mathrm{K}$ & - & - & & & & \\
\hline Total & 18.012 & 18.019 & & & & \\
\hline $\mathrm{Fa} / \mathrm{Fs}$ & 28.6 & 40.4 & & & & \\
\hline
\end{tabular}

Data in wt\%; b.d.: below detection limit, n.a.: not analyzed. grain appears to be displaced relative to the main crystal by $\sim 470 \mu \mathrm{m}$ (Fig. 3a). The melt vein, separating the two parts of the olivine, varies in widths from $<1$ to $\sim 25 \mu \mathrm{m}$ and contains abundant schlieren attesting turbulent flow (Fig. 3b). The melt vein displays a smooth gradual contact to olivine, shows characteristic quenched margins with smaller grain sizes at the veinolivine interface compared to those in the central part of the vein, and contains numerous Fe-sulfide and -oxide droplets as well as rounded to sub-rounded fragments of pyroxene, chromite, and phosphates entrained in the solidified melt of low porosity (Fig. 3b). In an $\sim 900 \mu \mathrm{m}$ wide region the melt vein splits up engulfing several up to $100 \mu \mathrm{m}$ sized, partially molten and dissolved olivine fragments most likely produced due to the brittle behavior of olivine during shearing (Fig. 3b). X-ray elemental mapping and line profiles across the vein show that the vein is compositionally zoned from the Fe-rich quenched margin to a more Si-rich central part. Defocused beam analyses of these regions attest that the vein is more olivine-normative close to the olivine-vein contact indicating partial melting of the sheared olivine, while the central part resembles more bulk rock composition with enhanced $\mathrm{Si} /(\mathrm{Fe}+\mathrm{Mg})$-ratios and high $\mathrm{Al}, \mathrm{Ca}, \mathrm{Cr}, \mathrm{Ti}, \mathrm{P}$, and $\mathrm{S}$ concentrations relative to olivine (Table 2). Additionally, a thin 300-600 nm wide zone of Mg-rich olivine separates the quenched margin of the vein from the sheared olivine host crystals (Figs. 4 and 5; Table 2).

The most striking features observed in the sheared olivine are thin lamellae extending from the olivine-vein interfaces into the host rock olivine megacryst (Fig. 4). Similar lamellae are also present in most of the engulfed olivine fragments. Lamellae are found all along the melt vein on both sides of the vein even if it narrows to less than $1 \mu \mathrm{m}$. The length of the lamellae is positively correlated with the width of the melt vein, i.e., the wider the vein, the longer the lamellae. X-ray elemental mapping shows that the 

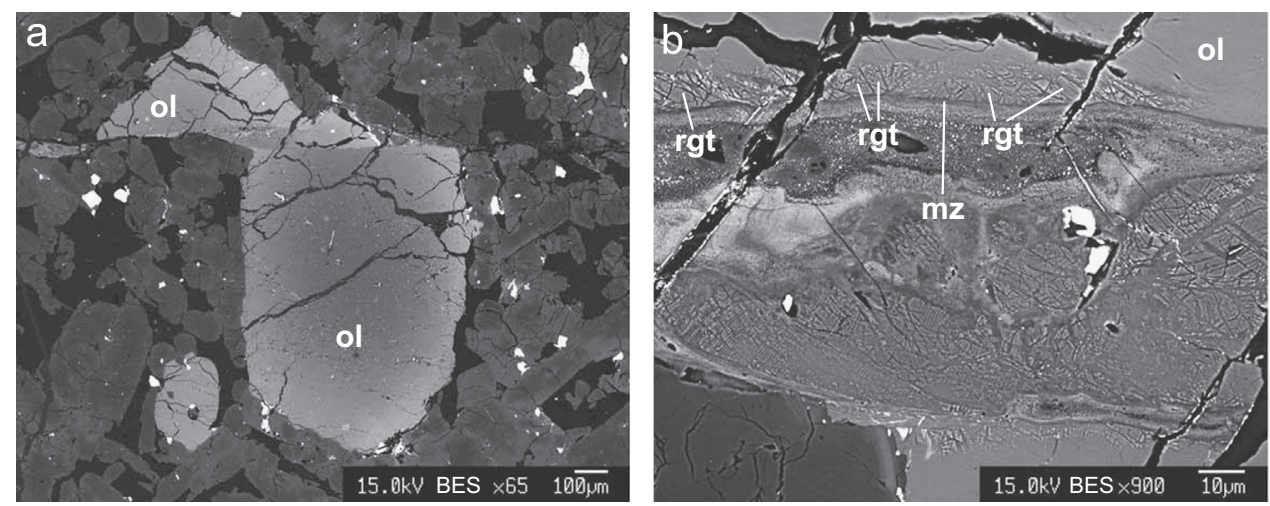

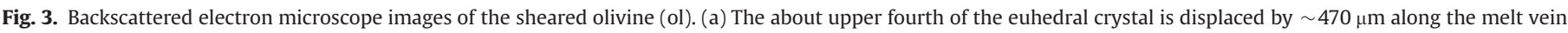

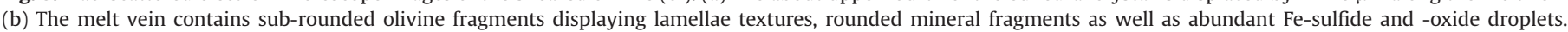

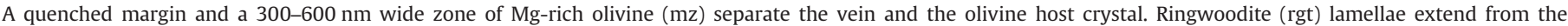
vein-olivine interface into the sheared olivine grain.
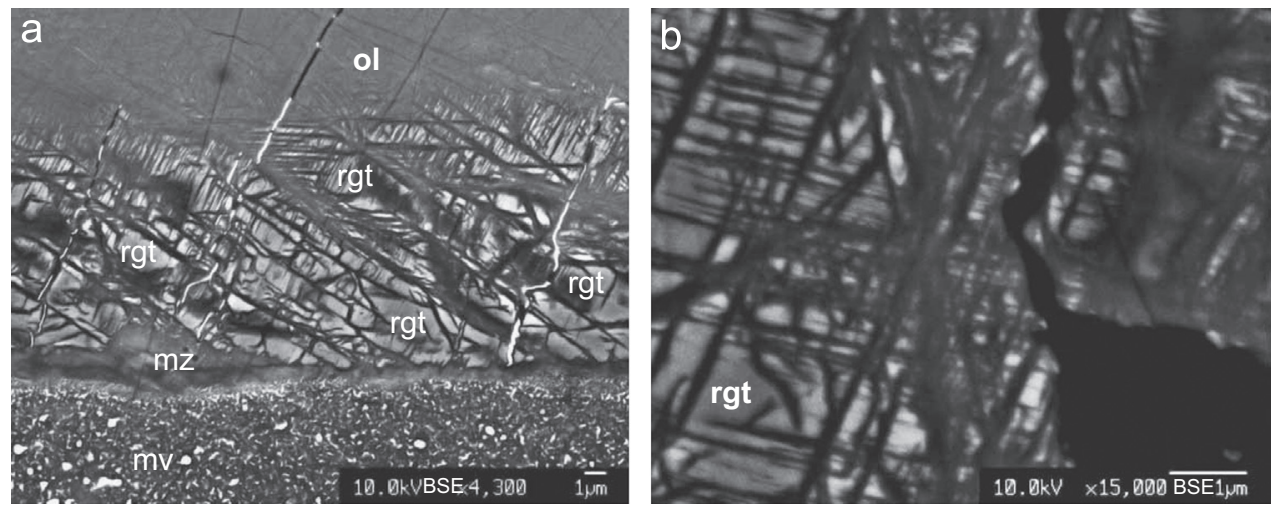

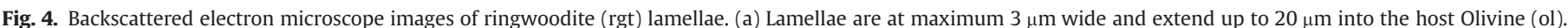

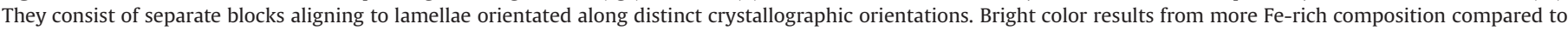
the host olivine. (b) Further away from the vein the lamellae fade out and appear to be composed of tiny sub- $\mu \mathrm{m}$ sized crystallites or thin parallel bands.

$\leq 1-3 \mu \mathrm{m}$ wide lamellae are often more Fe-rich than the host olivine and are separated from each other by thin zones of olivine more Mg-rich than the host olivine (Fig. 5). Lamellae and interstitial zones are both stoichiometrically olivine and show a maximum compositional difference of 13.9 mol\% Fa (Table 3). Bulk chemical composition of the Fe-rich lamellae and Mg-rich zones together coincide with the host rock olivine on a $\mu \mathrm{m}$-scale. The individual lamellae extend up to $20 \mu \mathrm{m}$ into the host olivine. Close to the vein they consist of up to $3 \mu \mathrm{m}$ broad aligned and sharply defined blocks separated from each other by ultra-thin 150$400 \mathrm{~nm}$ wide Mg-rich olivine while further away from the vein the outlines of the lamellae are less clearly defined (Figs. 4 and 5). Here the lamellae appear to be composed of tiny sub- $\mu \mathrm{m}$ sized crystallites or thin parallel bands orientated along distinct crystallographic orientations (Fig. 4).

Raman spectroscopic investigations show that the lamellae in the sheared olivine host crystals are ringwoodite (Fig. 6). The presence of the spinel-structured high-pressure polymorph of olivine is proven by the indicative Raman peaks at $\sim 796$ and $\sim 844 \mathrm{~cm}^{-1}$ (Fig. 6; McMillan and Akaogi, 1987). In contrast, the $\mathrm{Mg}$-rich zones interstitial between the ringwoodite lamellae are composed of olivine displaying the characteristic double peak at $\sim 826$ and at $\sim 853 \mathrm{~cm}^{-1}$ in the collected Raman spectra (Fig. 6; Kuebler et al., 2006). The intergrowth texture of both polymorphs is illustrated by Raman mapping of a $10 \times 10 \mu \mathrm{m}^{2}$ sized lamellaerich area displaying the intensities of the characteristic Raman peaks of ringwoodite and olivine (Fig. 6). Wadsleyite (McMillan and Akaogi, 1987) was not found in any spectra recorded. According to Raman spectroscopy the lamellae present in the enclosed and partially melted olivine fragments are exclusively $\alpha$-olivine; no high-pressure polymorph was found here.

Electron backscattered diffraction (EBSD) results acquired from a lamellae-rich area of approximately $20 \times 15 \mu \mathrm{m}^{2}$ confirms the presence of cubic ringwoodite blocks growing from the olivinemelt vein interface into the orthorhombic olivine host crystal (Fig. 7). The corresponding pole figures (Fig. 7) show a significant orientation spread of $10-15^{\circ}$ inside the ringwoodite crystals. No wadsleyite was detected with the EBSD measurements.

Stereographic projections pole figures corresponding to the measured olivine and ringwoodite areas (Fig. 7) indicate a special orientation relationship between ringwoodite and olivine: $\langle 001\rangle_{\mathrm{ol}}$ parallel with $\langle 110\rangle_{\mathrm{rw}}$ and $\langle 100\rangle_{\mathrm{ol}}$ parallel with $\langle 111\rangle_{\mathrm{rw}}$, i.e., during ringwoodite formation $\langle 001\rangle_{\mathrm{ol}}$ becomes $\langle 110\rangle_{\mathrm{rw}}$ and $\langle 100\rangle_{\mathrm{ol}}$ becomes $\langle 111\rangle_{\mathrm{rw}}$. This is consistent with earlier experimental results showing that during deformation under high pressure and high temperature dominantly the [001]\{hk0\} slip system is activated in olivine (Couvy et al., 2004; Mainprice et al., 2005).

\section{Discussion}

\subsection{Formation of Dar al Gani 670 shock veins}

Texture, mineralogy, and chemical composition of the melt veins in the non-sheared and sheared olivine allow their formation mechanisms to be constrained.

The highly porous melt vein cutting through the non-sheared olivine is compositionally enriched in $\mathrm{Al}, \mathrm{Ca}, \mathrm{Ti}, \mathrm{P}$, and $\mathrm{S}$ and shows 
a relative to olivine enhanced $\mathrm{Si} /(\mathrm{Fe}-\mathrm{Mg})$-ratio proving that the vein formed by melting of bulk rock regions with high modal abundance of pyroxene and not by shear-induced melting of the cut olivine. After formation in a larger melt volume, i.e., shock melt pocket, the melt was injected into either simultaneous with the melting event opening or into pre-existing fractures. The high
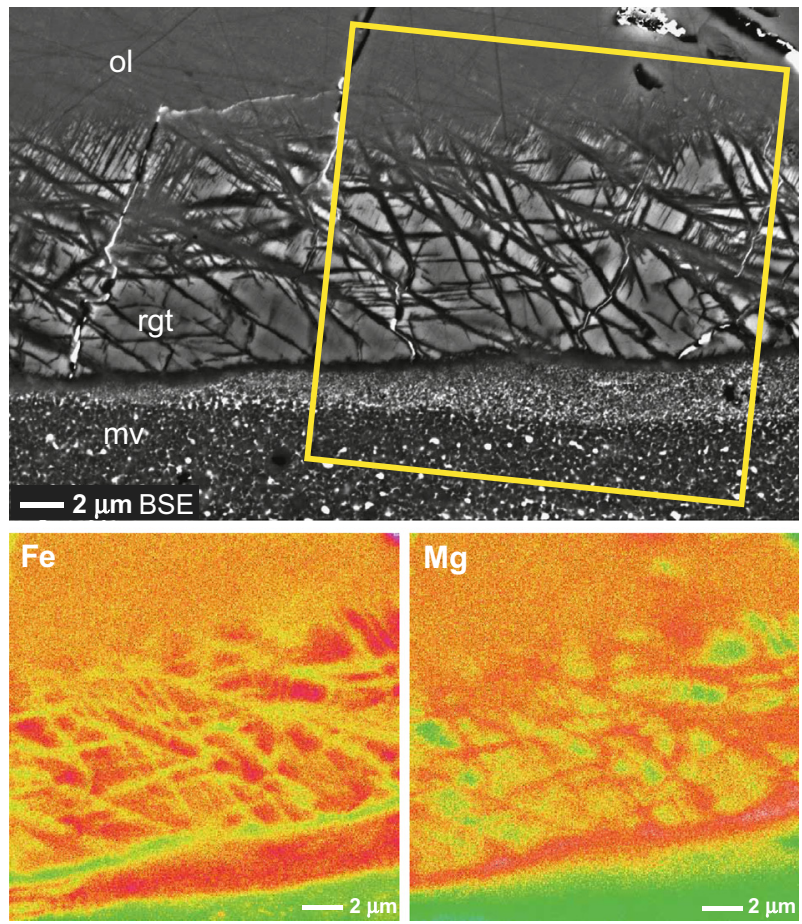

Fig. 5. Backscattered electron microscope image and X-ray elemental mappings of ringwoodite (rgt) lamellae and the olivine-melt vein (mv) interface. $\mathrm{Fe}$ and $\mathrm{Mg}$ distribution maps show Fe-rich lamellae separated by thin Mg-rich zones as well as the more Fe-rich quenched vein margin and a Mg-rich area directly at the veinolivine (ol) contact. primary porosity of the vein attests emplacement after pressure release allowing degassing of volatile melt components.

Texturally, the melt vein in the sheared olivine closely resembles those veins found in heavily shocked ordinary chondrites (e.g., Chen et al., 1996; Ohtani et al., 2004; Xie and Sharp, 2007). Composition, abundant schlieren, and entrained mineral fragments again testify that the melt formed by melting of bulk rock portion rather than locally by shearing of the olivine. After being generated the hot melt was injected into a pre-existing or simultaneously opening fracture. Melt emplacement took place during decompression before pressure dropped below $\sim 18 \mathrm{GPa}$ and at very high temperatures providing the kinetics for ringwoodite formation and causing partial melting of the adjacent olivine grains.

\subsection{High-pressure mineral grains in shock veins}

Typical high-pressure phase transformations, i.e., olivine to wadsleyite and ringwoodite, enstatite to majorite or clinoenstatite, plagioclase to hollandite, and Ca-pyroxene to Ca-rich majorite as they occur within or adjacent to shock veins in ordinary chondrites have frequently been used to constrain the pressure and temperature regime in the melt veins and pockets of the meteorites during shock as well the shock-pressure duration (e.g., Sharp and DeCarli, 2006 and references therein). The latter is important as it allows the minimum size of the impactor to be constrained. Although these values are specific for each meteorite and particular phase assemblage, pressure ranges of $\sim 18-28 \mathrm{GPa}$, temperatures of $2000-2300{ }^{\circ} \mathrm{C}$, and pressure durations at the microseconds to meterseconds scale are typically deduced (e.g., Beck et al., 2005; Xie et al., 2006; Xie and Sharp, 2007; Tschauner et al., 2009). In the vast majority of the settings ringwoodite formed during shock metamorphism via interface-controlled solid-state transformation not involving significant $\mathrm{Fe}-\mathrm{Mg}$ diffusion. In the two known cases in which ringwoodite formed by fractional crystallization from a shock-induced melt which implies intensive Fe-Mg-interchange similar P-T-t-conditions were obtained (Miyahara et al., 2008; Fritz

Table 3

Representative analyses of the upper part of the sheared olivine and the different types of lamellae.

\begin{tabular}{|c|c|c|c|c|c|c|c|}
\hline & Olivine upper part & Olivine upper part & Olivine in melt vein & Fe-rich ol-lamella & Interstitial olivine & Ringwoodite1 & Ringwoodite 2 \\
\hline $\mathrm{SiO}_{2}$ & 36.39 & 36.06 & 35.94 & 35.14 & 37.05 & 36.36 & 35.89 \\
\hline $\mathrm{TiO}_{2}$ & b.d. & b.d. & b.d. & 0.06 & b.d. & 0.05 & b.d. \\
\hline $\mathrm{Al}_{2} \mathrm{O}_{3}$ & 0.25 & 0.03 & 0.08 & 0.03 & b.d. & b.d. & b.d. \\
\hline $\mathrm{Cr}_{2} \mathrm{O}_{3}$ & 0.06 & 0.08 & 0.1 & 0.06 & 0.08 & 0.09 & 0.07 \\
\hline $\mathrm{FeO}$ & 30.38 & 34.34 & 31.19 & 40.66 & 30.81 & 32.22 & 33.35 \\
\hline $\mathrm{MnO}$ & 0.54 & 0.51 & 0.6 & 0.44 & 0.62 & 0.56 & 0.54 \\
\hline $\mathrm{MgO}$ & 30.91 & 28.32 & 30.77 & 23.64 & 31.75 & 29.73 & 28.79 \\
\hline $\mathrm{CaO}$ & 0.41 & 0.4 & 0.35 & 0.62 & 0.37 & 0.37 & 0.42 \\
\hline $\mathrm{Na}_{2} \mathrm{O}$ & 0.03 & - & b.d. & 0.02 & b.d. & 0.05 & b.d. \\
\hline $\mathrm{K}_{2} \mathrm{O}$ & b.d. & - & b.d. & b.d & b.d. & b.d. & b.d. \\
\hline Total & 98.97 & 99.74 & 99.03 & 100.67 & 100.68 & 99.43 & 99.06 \\
\hline \multicolumn{8}{|c|}{ Formula } \\
\hline 0 & 24 & 24 & 24 & 24 & 24 & 24 & 24 \\
\hline $\mathrm{Si}$ & 5.994 & 6.008 & 5.945 & 5.990 & 5.998 & 6.014 & 5.998 \\
\hline $\mathrm{Ti}$ & - & - & - & 0.007 & - & 0.006 & - \\
\hline $\mathrm{Al}$ & 0.049 & 0.005 & 0.015 & 0.006 & - & - & - \\
\hline $\mathrm{Cr}$ & 0.008 & 0.010 & 0.012 & 0.007 & 0.010 & 0.012 & 0.009 \\
\hline $\mathrm{Fe}$ & 4.184 & 4.784 & 4.315 & 5.797 & 4.171 & 4.457 & 4.661 \\
\hline $\mathrm{Mn}$ & 0.075 & 0.071 & 0.084 & 0.064 & 0.086 & 0.079 & 0.077 \\
\hline $\mathrm{Mg}$ & 7.589 & 7.032 & 7.586 & 6.007 & 7.662 & 7.332 & 7.172 \\
\hline $\mathrm{Ca}$ & 0.072 & 0.071 & 0.061 & 0.113 & 0.064 & 0.066 & 0.073 \\
\hline $\mathrm{Na}$ & 0.010 & - & - & 0.007 & - & 0.017 & - \\
\hline $\mathrm{K}$ & - & - & - & - & - & - & - \\
\hline Total & 17.981 & 17.981 & 18.018 & 17.998 & 17.991 & 17.983 & 17.990 \\
\hline $\mathrm{Fa}$ & 35.5 & 40.5 & 36.3 & 49.1 & 35.2 & 37.8 & 39.4 \\
\hline
\end{tabular}

Data in wt\%; b.d.: below detection limit. 

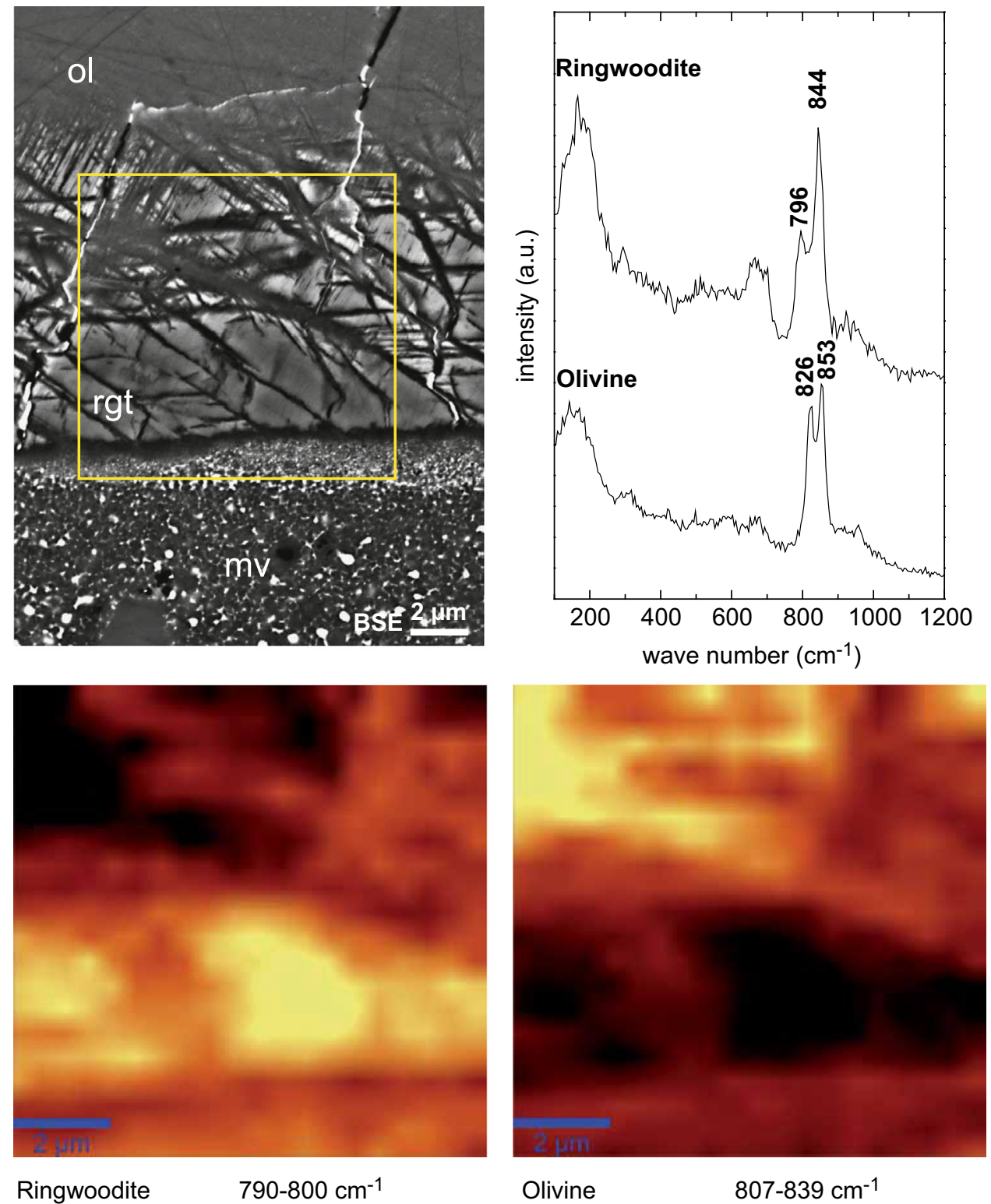

Ringwoodite

$790-800 \mathrm{~cm}^{-1}$

Olivine

$807-839 \mathrm{~cm}^{-1}$

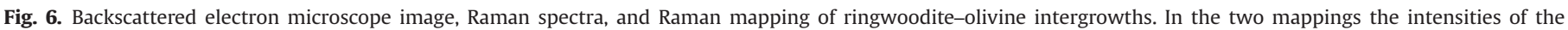
characteristic wavelengths of ringwoodite (rgt) and olivine (ol), respectively are shown; mv=melt vein.

and Greshake, 2009) pointing to very rapid crystal growth and ultrafast mass transport (Tschauner et al., 2009).

Solid-state transformation of olivine either takes place as incoherent or coherent growth with the first one being much faster (e.g., Sharp and DeCarli, 2006). Most ringwoodite in shockinduced melt veins occurs as polycrystalline aggregates attesting fast incoherent growth. However, few occurrences of lamellar ringwoodite have been reported.

Chen et al. (2004) report ringwoodite lamellae in olivine within and adjacent to a shock vein in the L6 chondrite Sixiangkou. They suggest that crystallographic orientation and chemical composition of the lamellae which is slightly more Fe-rich than the host olivine are best explained by intracrystalline diffusion-controlled coherent transformation. Applying experimental data from Kerschhofer et al. (1996) it is concluded that high temperatures and pressures prevailed for several seconds for the growth of the ringwoodite lamellae (Chen et al., 2004). Similar pressure durations were calculated by Ohtani et al. (2004) for the growth of ringwoodite lamellae with identical composition as their host olivine for the Yamato 791384 chondrite.
In contrast, formation of polycrystalline ringwoodite lamellae in olivine within a melt vein of Tenham L6 chondrite seems to be inconsistent with coherent transformation (Xie and Sharp, 2007). Ringwoodite formation preferentially along specific crystallographic defect planes of the host is proposed and the time to grow a $1 \mu \mathrm{m}$ ringwoodite crystal calculated to $100 \mathrm{~ms}$ at $1600 \mathrm{~K}$ (Xie and Sharp, 2007).

Fracture-related ringwoodite lamellae were reported from olivine in shock veins again of the Sixiangkou meteorite (Chen et al., 2006). The lamellae are more Fe-rich than the host olivine and consist of polycrystalline aggregates of ringwoodite. Distinct Fe-poor zones on both sides of the lamellae separate them from the host olivine. The authors propose a new mechanism of intracrystalline phase transformation involving incoherent nucleation and $\mathrm{Fe}-\mathrm{Mg}$-interchange between olivine and ringwoodite (Chen et al., 2006). Experimental data on Fe-Mg diffusivity is used to constrain the shock pressure for the growth of the lamellae to several minutes (Chen et al., 2006).

Microstructural investigations of compositionally zoned, i.e., $\mathrm{Mg}$-rich core and Fe-rich rims, ringwoodite lamellae in Sixiangkou 

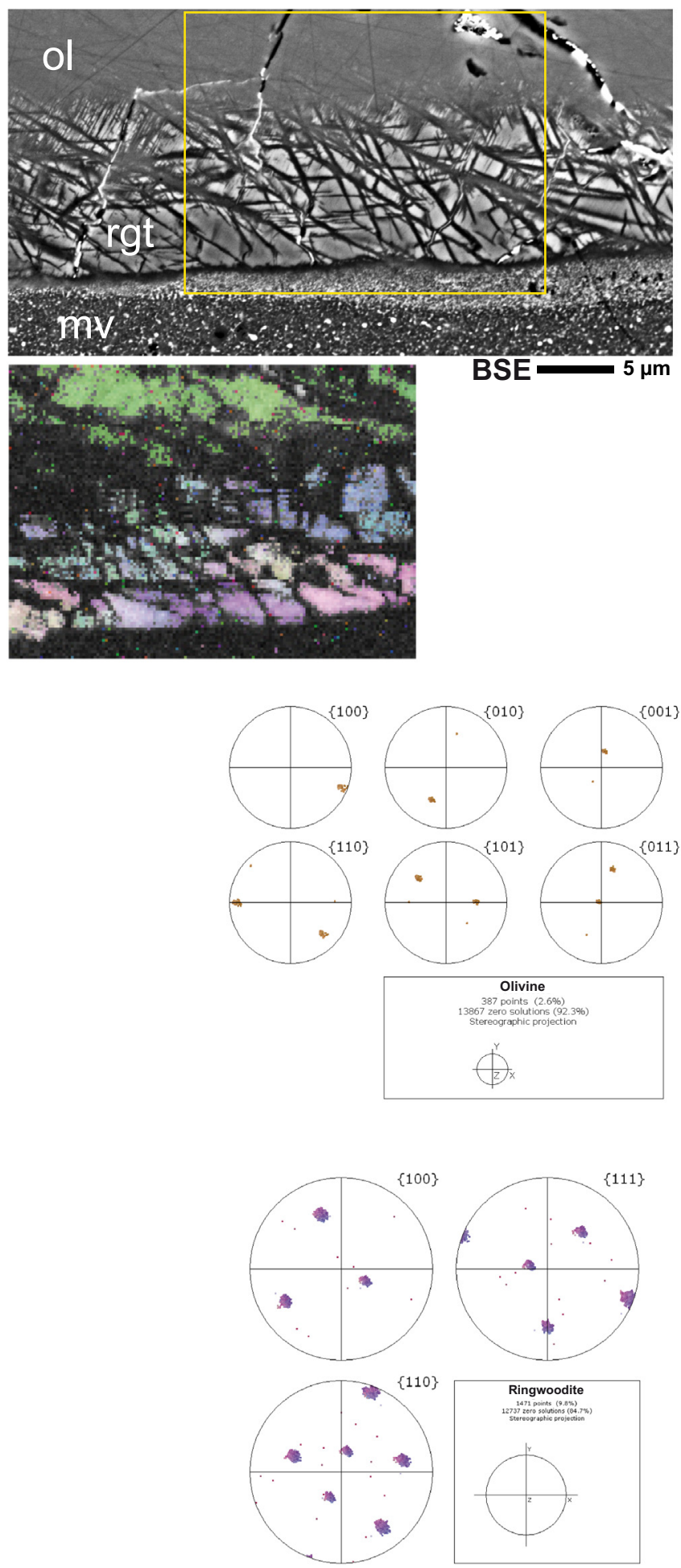

Fig. 7. Backscattered electron microscope image of ringwoodite lamellae and EBSD orientation map (IPFx) of the highlighted area showing ringwoodite lamellae in the lower half (blue-purple region) and the olivine matrix in the upper half (green region). The corresponding pole figures (stereographic projections) indicate the presence of a special orientation relationship between ringwoodite and olivine: $\langle 001\rangle_{\mathrm{ol}}$ parallel with $\langle 110\rangle_{\mathrm{rw}}$ and $\langle 100\rangle_{1}$ parallel with $\langle 111\rangle_{\mathrm{rw}}$; in other words during ringwoodite formation $\langle 001\rangle_{\mathrm{ol}}$ becomes $\langle 110\rangle_{\mathrm{rw}}$ and $\langle 100\rangle_{\mathrm{ol}}$ becomes $\langle 111\rangle_{\mathrm{rw}}$. (For interpretation of the references to color in this figure legend, the reader is referred to the web version of this article.)

suggest that the intracrystalline transformation of olivine proceeds through Fe-Mg diffusion during ringwoodite growth. A two stage mechanism is inferred with a firstly formed thin layer of small crystallites being overgrown on both sides by coarser ringwoodite crystallites (Chen et al., 2007). For a ringwoodite lamella $\sim 2 \mu \mathrm{m}$ in width, the duration of diffusion at $1500{ }^{\circ} \mathrm{C}$ should be $\sim 17 \mathrm{~s}$ (Chen et al., 2007).

Coherent and subsequent incoherent growth has been proposed for growth of ringwoodite lamellae in Yamato 791384 chondrite (Miyahara et al., 2010). It is argued that a thin layer of coherent ringwoodite followed by a thicker layer of incoherent ringwoodite formed within $\sim 4 \mathrm{~s}$ to produce the $23 \mu \mathrm{m}$ wide ringwoodite zone observed (Miyahara et al., 2010).

Recently, Walton (2013) reported lamellar ringwoodite within and around a shock vein cross-cutting an olivine megacryst in lithology A of the Martian meteorite EETA 79001. The lamellae show similarities with those described in the present study, especially as they are more Fe-rich than the host olivine and are composed of sub- $\mu \mathrm{m}$ sized ringwoodite grains rather than being single crystals (Walton, 2013). Formation of the ringwoodite lamellae is attributed to heterogeneous nucleation and a diffusion-limited growth mechanism supposed to operate at very high strain rates (Xie and Sharp, 2007; Walton, 2013). This, so far poorly understood mechanism seems to be strongly related to shock-induced grain size reduction and planar fractures, enhancing diffusion rates and providing nucleation sites for ringwoodite formation (Xie and Sharp, 2007; Greshake et al., 2011; Walton, 2013).

\subsection{Formation and preservation of ringwoodite lamellae in Dar al Gani 670}

According to static high-pressure experiments and thermodynamic calculations, forsteritic olivine converts at $1400{ }^{\circ} \mathrm{C}$ and $\sim 18 \mathrm{GPa}$ into its cubic high-pressure polymorph ringwoodite which is then stable until $\sim 23 \mathrm{GPa}$ before it breaks down into ferropericlase and ( $\mathrm{Mg}, \mathrm{Fe})$ $\mathrm{SiO}_{3}$-perovskite (Akaogi et al., 1989 and references therein). Increasing Fe-content of olivine favors ringwoodite formation and generally allows transformation at even lower pressures and temperatures (e.g., Wang et al., 1997; Akaogi et al., 1989). The olivine-ringwoodite transformation is a reversible process. Thermal annealing experiments and observations on naturally heated ringwoodite showed that ringwoodite back reacts to olivine at low pressures at temperatures above $900{ }^{\circ} \mathrm{C}$ (Ming et al., 1991; Kimura et al., 2003).

In contrast to static high-pressure experiments and natural high-pressure environments, e.g. the Earth's mantle, during an impact event the duration of shock compression is significantly lower and, depending on the size of the impactor, only in the order of ms to $100 \mathrm{~ms}$. Thus, shock-induced formation and preservation of ringwoodite requires

(1) heating to very high temperatures, i.e., $>1427{ }^{\circ} \mathrm{C}$ (Xie and Sharp, 2007) to provide the rapid transformation kinetics required and

(2) quenching to low temperatures during shock compression and subsequent decompression within the ringwoodite stability field to suppress back reaction to olivine.

Only locally occurring thin shock melt veins can undergo this rapid change in temperature and, thus, provide the unique conditions required for ringwoodite formation and preservation. Our findings in DaG 670 are in excellent agreement with this. The occurrence of ringwoodite in the sheared olivine crystal is restricted to a narrow at maximum $20 \mu \mathrm{m}$ wide zone at the olivine-melt vein interface where temperatures were high enough to allow its formation. Thermal conduction between the superheated melt and the much cooler olivine grain serving as a heat sink was fast enough to quench the spinel-structured highpressure polymorph within its stability field. Further inward the olivine host it was apparently too cold to provide the 
transformation kinetics required. The DaG 670 host rock can generally serve as a heat conductor to quickly lower the temperatures below $900{ }^{\circ} \mathrm{C}$ to preserve ringwoodite because shock pressures of 40-45 GPa correspond to a post shock temperature increase of only $\sim 470 \pm 100 \mathrm{~K}$ above the initial temperature of the Martian rock (Fritz et al., 2005).

Lamellae present in the large and partially melted olivine fragments enclosed in the melt vein are exclusively $\alpha$-olivine most likely representing back-reacted former ringwoodite evidencing that the temperature in the much thicker brecciated area of the vein stayed long enough above the transformation temperature to allow back-reaction but without erasing compositional differences. The absence of cracks around the olivine fragments indicates that the melt vein was still ductile during back-reaction of ringwoodite and, thus, able to accomplish the volume change of $6 \%$.

The cooling time $(t)$ of a melt vein can be approximated by $t=L^{2} / \alpha$ with $L=$ width of melt vein; and $\alpha=$ thermal diffusivity (i.e., thermal conductivity divided by density and specific heat capacity at constant pressure; see Fritz and Greshake, (2009) and references therein). Considering a thermal diffusivity of $10^{-6} \mathrm{~m}^{2} / \mathrm{s}$, a $25 \mu \mathrm{m}$ wide melt vein quenches in $0.63 \mathrm{~ms}$ (Fritz and Greshake, 2009; see Fig. 4). Thus, the hot melt very likely heated up the adjacent olivine crystal for less than $1 \mathrm{~ms}$, constraining the time span in which ringwoodite formed and the pronounced compositional differences between the host olivine and Fe-rich lamellae developed.

BSE imaging at high resolution showed that the ringwoodite lamellae are polycrystalline rather than single-crystal lamellae and composed of tiny sub- $\mu$ m sized crystallites or thin parallel bands. This microstructure is consistent with incoherent solid-state transformation of olivine to ringwoodite. Additionally, the chemical difference between the more Fe-rich ringwoodite lamellae and especially the Mg-rich interstitial olivine-zones implies Fepartitioning from olivine into ringwoodite over a range of up to $3 \mu \mathrm{m}$ (max. widths of lamellae) and attests diffusion-controlled ringwoodite growth.

Diffusion-controlled ringwoodite growth is kinetically much slower than interface-controlled solid-state transformation and requires either very long shock durations of several seconds up to even minutes or ultrafast diffusive mass transport.

Experimental $\mathrm{Mg}-\mathrm{Fe}$ diffusion coefficients in ringwoodite $\left(5.6 \times 10^{-14} \mathrm{~m}^{2} / \mathrm{s}\right)$ and olivine $\left(2 \times 10^{-15} \mathrm{~m}^{2} / \mathrm{s}\right)$ were previously used to estimate the time duration of diffusion during ringwoodite lamellae formation at $1500{ }^{\circ} \mathrm{C}$ (Chen et al., 2007). The calculations suggest that it takes $\sim 17 \mathrm{~s}$ to grow a $2 \mu \mathrm{m}$ wide Fe-rich ringwoodite lamellae and $\sim 12 \mathrm{~s}$ to form a $300 \mathrm{~nm}$ wide Mg-rich interlamellar zone via diffusion-controlled growth (Chen et al., (2007) and references therein). The duration of shock compression in Martian meteorites (rock fragments ejected by spallation) is related to the pre-impact burial depth below the Martian surfaces and, thus, indirectly allows to constrain the size of the impactor (Fritz and Greshake, 2009). Time scales in the order of seconds would imply projectile sizes of $>10 \mathrm{~km}$ which are highly unrealistic. Recently, estimates for a shock pressure duration of $50 \mathrm{~ms}$ in the olivine-phyric shergottite Tissint were used to propose a source crater of $\sim 90 \mathrm{~km}$ diameter (Baziotis et al., 2013). However, Martian meteorites display only $4 \pi$ (small body) cosmic ray exposure histories and cosmic ray exposure ages, which constitute seven distinct clusters of petrologically similar meteorites (Eugster et al., 2002; Christen et al., 2005; Nishiizumi et al., 2012). A source crater $\sim 90 \mathrm{~km}$ in diameter, thus, appears as too large as there are not enough large young craters on Mars to account for all these different ejection events (Gladman, 1997; Head et al., 2002; Artemieva and Ivanov, 2004; Fritz et al., 2007). All high-pressure assemblages in Martian meteorites evidence shock pressure duration during ejection from the Martian surface of $\leq 50 \mathrm{~ms}$, setting an upper time limit for the formation and preservation of highpressure phases in these meteorites. In the present case, however, heating of the olivine is due to heat transfer from the injected melt and is not related to the pulse length of shock compression. The formation time of ringwoodite can, thus, be deduced from the thickness of the melt vein, which only provides heat to the adjacent olivine crystal for $<1 \mathrm{~ms}$.

Ringwoodite lamellae in Dar al Gani 670 occur only in case of the sheared olivine; the non-sheared olivine also cut by a melt vein does not contain any high-pressure polymorphs. This strongly advocates that for the diffusion controlled formation of ringwoodite lamellae in less than $1 \mathrm{~ms}$ shearing plays an important role.

\subsection{The role of shearing}

High-pressure diffusion experiments suggest that Fe-Mg interdiffusion is much faster in wadsleyite and ringwoodite compared to olivine with a jump in diffusivity of $\sim 3$ orders of magnitude across the phase transition (Farber et al., 1994, 2000; Béjina et al., 2003) and may also strongly depend on the mineral composition with diffusion rates increasing exponentially with Fe-content (Holzapfel et al., 2009). However, it is unlikely that these effects alone can account for the extremely fast diffusion required to grow the ringwoodite lamellae observed.

Several mechanisms are known to enhance diffusion rates in minerals. Generally, grain boundary diffusion is significantly faster than volume diffusion through the crystal lattice (e.g., Ganguly, 2002). While both mechanisms are strongly temperature dependent with increasing diffusion rates at higher temperatures, in case of grain boundary diffusion, grain size reductions, formation of sub-grain boundaries as well as high densities of lattice defects, e.g., dislocations and fractures serving as pathways for atoms may increase diffusion rates and result in faster Fe-Mg interchange (e.g., Xie and Sharp, 2007; Greshake et al., 2011; Walton, 2013).

DaG 670 is part of a strewn field of eight paired fragments of which DaG 476, DaG 489, and DaG 670 have been intensely studied regarding their mineralogy, petrology, and chemistry (Greshake and Stöffler, 1999; Folco and Franchi, 2000; Folco et al., 2000; Zipfel et al., 2000; Mikouchi et al., 2001). All samples studied are heavily affected by shock metamorphism and share the following shock effects. As discernible by optical microscopy, olivine displays a high density of planar and irregular fractures, extremely strong mosaicism, fine planar deformation features as well as an intense brownish staining. Pyroxene is characterized by a high density of irregular fractures, strong mosaicism, small irregular planar deformation features, and numerous shock induced twins parallel (100). Plagioclase is exclusively transformed to maskelynite. All samples contain up to several $\mathrm{mm}$ sized shock melt pockets and are crosscut by networks of dark shock melt veins.

The microstructure of shock effects in olivine was previously studied by transmission electron microscopy (TEM) using the paired meteorite DaG 476 (Greshake and Stöffler, 1999 and unpublished data; Fig. 8). Apart from the wide open fractures already visible by optical microscopy, TEM revealed the presence of numerous planar micro-fractures with misfits of only up to half the (010) olivine lattice plane ( $\sim 0.5 \mathrm{~nm}$; Fig. $8 \mathrm{c})$. According to high-resolution TEM, the high degree of mosaicsim results from small $\sim 100 \mathrm{~nm}$ to few micrometers sized domains or sub-grains within the olivine crystal rotated by up to $65^{\circ}$ with respect to each other (Fig. 8c). Olivine is also characterized by a high density $\left(\sim 10^{14} \mathrm{~m}^{-2}\right)$ of screw dislocations with Burgers vector [001] (Fig. 8b); in several areas within the crystal the dislocations are concentrated in walls which are transitional to sub-grain boundaries (Fig. 8d). Olivine additionally contains fine up to $\sim 0.5 \mu \mathrm{m}$ wide microstructures resembling close similarities with 

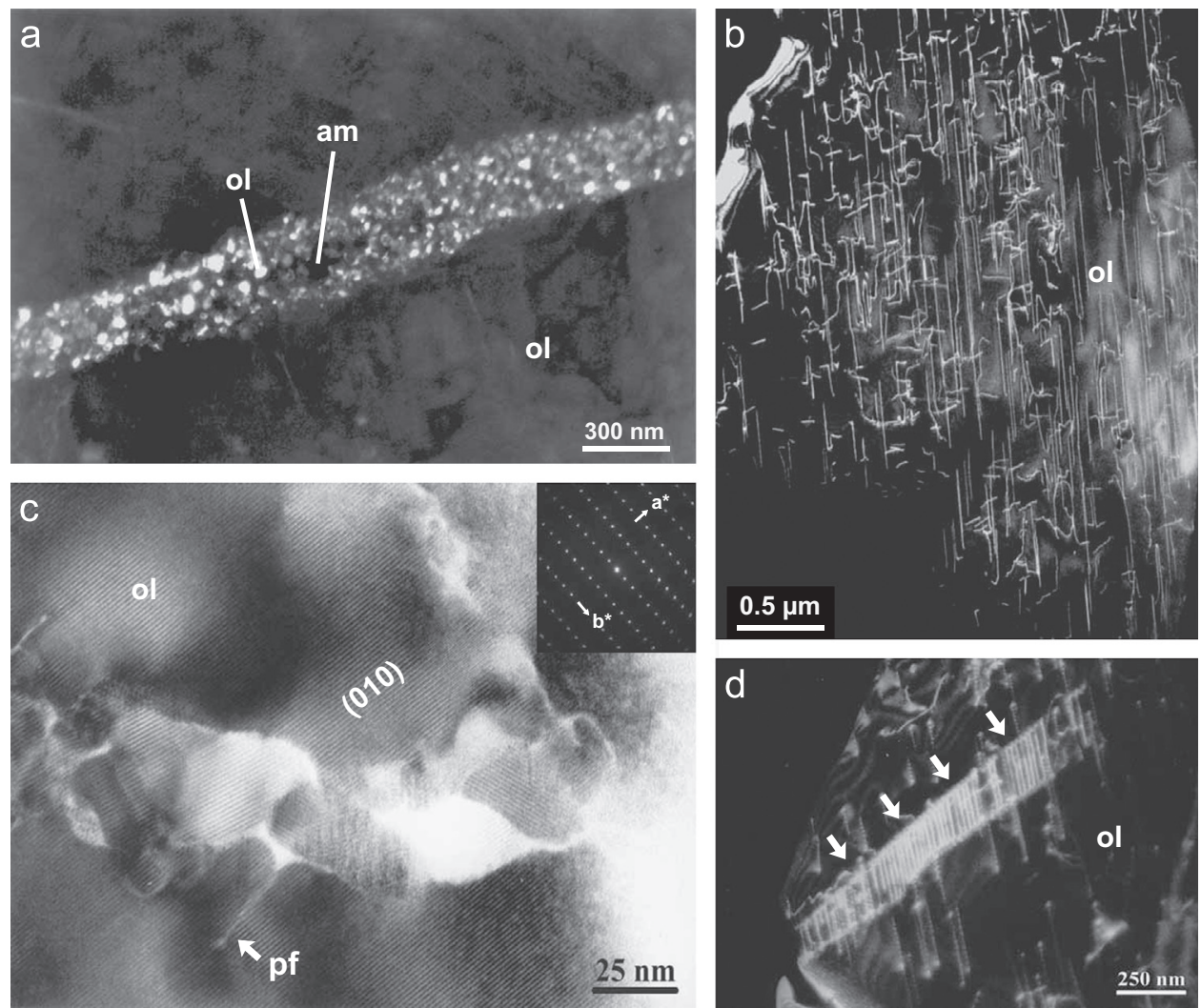

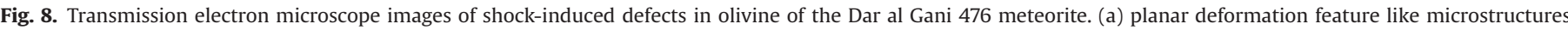

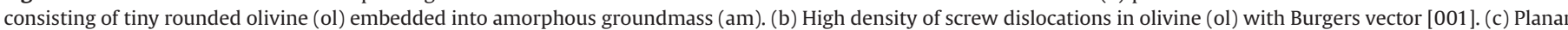

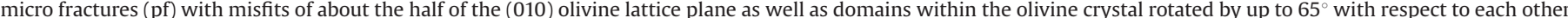

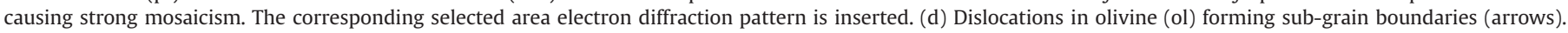

planar deformation features (PDF) known from quartz and other minerals. The structures are composed of tiny rounded olivine embedded into amorphous material (Fig. 8a).

DaG 670 and DaG 476 are fragments of the same meteorite fall and all rock-forming minerals display identical shock effects at the scale of optical microscopy. It, thus, seems reasonable to assume that they also share the microstructural shock features observed in olivine as described above. In addition to these, the olivine megacryst in DaG 670 was sheared along the shock-induced melt vein.

The bulk composition of the melt vein attests that the hot melt was injected into a preexisting fracture and that shearing of the olivine predates melting. Only very little of the olivine crystal was melted by the intruding bulk rock melt implying a maximum melt temperature of $\sim 1600{ }^{\circ} \mathrm{C}$. However, as the olivine-ringwoodite transformation is an exothermic reaction accompanied by a volume reduction of $6 \%$ (Green, 2007) temperature may have locally exceeded this value.

Brittle behavior of olivine during opening of the fracture and shearing is confirmed by large olivine fragments found within in the vein. The region between the two olivine counterparts may, thus, be characterized as a "crushed zone" flooded by hot bulk rock melt.

From these observations we infer that shear-induced effects are decisive for diffusion-controlled growth of ringwoodite lamellae within a very short time span. Lattice defects induced by shearing at high strain rates serve as nucleation sides and trigger ringwoodite formation at the hot olivine-melt contacts where rapid transformation kinetics is provided. Grain size reduction due to shear-fracturing together with numerous micro-fractures, high dislocation densities, sub-grain boundaries, strong mosaicism resulting from rotated crystals domains, and planar deformation features allow a rapid $\mathrm{Fe}-\mathrm{Mg}$ interchange possibly enhanced by the shock induced high particle velocities in the order of kilometer per second.

\subsection{Ringwoodite formation in subducting slabs}

Olivine is the most abundant mineral in the Earth's upper mantle and essentially controls its rheology (e.g., Mainprice et al., 2005). Deformation and phase transformation mechanisms of olivine are, thus, of considerable interest. Shear-experiments conducted at low strain $(\gamma \sim 0.3)$ on olivine aggregates at $11 \mathrm{GPa}$ and $1400{ }^{\circ} \mathrm{C}$, conditions that correspond to those at $\sim 330 \mathrm{~km}$ depth, have shown that deformation takes place by dislocation creep, with dominant activation of the [001] $\{h k 0\}$ slip system (Couvy et al., 2004; Mainprice et al., 2005). Although strain rates during shock metamorphism are significantly higher and typically in the range of $10^{3}-10^{6} \mathrm{~s}^{-1}$ (e.g., Spray, 1995), in the sheared olivine of DaG 670 also the [001]\{hk0\} slip system is activated suggesting that independent from strain rates [001]\{hk0\} might be the dominant slip system operating under high pressures and temperatures.

Phase transformation of (metastable) olivine into ringwoodite has been considered a major mechanism for deep earthquakes in subduction zones at 400-700 km depth (Frohlich, 1994; Green, 2007). Under such extreme pressure and temperature conditions generation of earthquakes is explained by high-pressure shearing instabilities that involve breakdown of olivine leading to formation of micro-anticracks filled with denser ringwoodite. These cracks interact with each other through the elastic strain fields at their tips and - in a runaway process - culminate in initiation of a fault finally leading to catastrophic shear failure (Green, 2007).

Our results suggest that once high-pressure shear failure was initiated, shearing by itself enhances ringwoodite formation due to the production of lattice defects that serve as nucleation sides for the high-pressure polymorph. By triggering the olivine-ringwoodite phase transformation shearing, thus, supports the runaway process of material failure that may lead to deep earthquakes. 


\section{Summary and conclusions}

In the Martian shergottite Dar al Gani 670 two olivine crystals were found cut by shock-produced melt veins. In one of the grains the upper part is displaced along the shock vein while in the other grain no shearing is observed. In both cases bulk rock chemical composition of the melt indicates that fracturing predates melt formation and that the melt was injected into preexisting fractures. Only in the sheared olivine small lamellae of ringwoodite grow from the olivine-melt interface into the host crystals. The lamellae are orientated along specific crystallographic orientations and are mostly more Fe-rich than the host olivine. Olivine fragments entrained in the melt vein also show lamellae structure but consist solely of $\alpha$-olivine. It is inferred that upon pressure release from $\sim 45 \mathrm{GPa}$, ringwoodite lamellae started to nucleate at $\sim 23 \mathrm{GPa}$ and max. $1600{ }^{\circ} \mathrm{C}$ at the hot olivine-melt contacts and grew inward the olivine crystals. While ringwoodite was rapidly cooled and, thus, preserved within the relatively cold large olivine crystal, it back-reacted to $\alpha$-olivine within the warmer vein. The lamellae consist of small bands and blocks rather than representing single crystals. Texture and Fe-rich composition indicate that they formed via incoherent diffusion-controlled growth. According to experimental diffusion coefficients it takes $\sim 17 \mathrm{~s}$ to grow $2 \mu \mathrm{m}$ wide Fe-rich ringwoodite lamellae. Such durations correspond to projectile sizes of $>10 \mathrm{~km}$ which are highly unrealistic for Martian meteorites. It is suggested that a combination of high particle velocities and shock-induced defects, i.e., wide open fractures, micro-fractures, high dislocation densities, subgrain boundaries, rotated crystal domains (mosaicism), and planar deformation features lead to enhanced diffusion rates. Most significantly, shearing caused grain size reduction allowing rapid Fe-Mg interchange and induced lattice defects serving as nucleation sites for ringwoodite. Crystallographic orientation of ringwoodite lamellae indicate that during shock deformation at very high strain rates the $[001]\{h k 0\}$ slip system was activated in olivine. This result is consistent with shear experiments at low strain showing that in olivine [001] $h k 0\}$ is the dominant slip system operating under high pressures and temperatures. Highpressure shear instabilities of olivine at subduction zones in 400 $700 \mathrm{~km}$ depth are considered being responsible for deep earthquakes. At such $p-T$-conditions, breakdown of olivine results in formation of (ringwoodite filled) micro-anticracks which interact with each other finally leading to catastrophic shear failure. Our results strongly suggest that shearing itself contributes to a runaway process of enhanced ringwoodite formation and, thus, reinforces catastrophic material failure that may result in deep earthquakes.

\section{Acknowledgments}

We are grateful to Luigi Folco (Museo Nazionale dell'Antartide, Università di Siena, Italy) for providing the thin section of Dar al Gani 670. Constructive reviews by Erin Walton and an anonymous reviewer improved the quality of the manuscript and are gratefully acknowledged. This work was partially supported by the Helmholtz Alliance Planetary Evolution and Life WP3200.

\section{References}

Akaogi, M., Ito, E., Navrotsky, A., 1989. Olivine modified spinel-spinel transitions in the system $\mathrm{Mg}_{2} \mathrm{SiO}_{4}-\mathrm{Fe}_{2} \mathrm{SiO}_{4}$ : calorimetric measurements, thermochemical calculation, and geophysical application. J. Geophys. Res. 94, 15671-15685.

Artemieva, N., Ivanov, B., 2004. Launch of Martian meteorites in oblique impacts. Icarus 171, 84-101.
Baziotis, I.P., Yang, L., DeCarli, P.S., Melosh, H.J., McSween, H.Y., Bodnar, R.J., Taylor, L.A., 2013. The Tissint Martian meteorite as evidence for the largest impact excavation. Nat. Commun. 4, 1404, http://dx.doi.org/10.1038/ncomms2414.

Beck, P., Gillet, P., Gautron, L., Danielle, I., El Goresy, A., 2004. A new natural highpressure $(\mathrm{Na}, \mathrm{Ca})$-hexaluminosilicate $\left[\left(\mathrm{Ca}_{x} \mathrm{Na}_{1-x}\right) \mathrm{Al}_{3+\chi} \mathrm{Si}_{3-x} \mathrm{O}_{11}\right]$ in shocked Martian meteorites. Earth Planet. Sci. Lett. 219, 1-12.

Beck, P., Gillet, P., El Goresy, A., Mostefaoui, S., 2005. Timescales of shock processes in chondritic and Martian meteorites. Nature 435, 1071-1074.

Béjina, F., Jaoul, O., Liebermann, R.C., 2003. Diffusion in minerals at high pressure: a review. Phys. Earth Planet. Inter. 139, 3-20.

Binns, R.A., Davis, R.J., Reed, S.J.B., 1969. Ringwoodite, natural ( $\mathrm{Mg}, \mathrm{Fe})_{2} \mathrm{SiO}_{4}$ spinel in the Tenham meteorite. Nature 221, 943-944

Chen, M., El Goresy, A., Gillet, P., 2004. Ringwoodite lamellae in olivine: clues to olivine-ringwoodite phase transition mechanisms in shocked meteorites and subducting slabs. Proc. Natl. Acad. Sci. 101, 15033-15037.

Chen, M., Chen, J., Xie, X., Xu, J., 2007. A microstructural investigation of natural lamellar ringwoodite in olivine of the shocked Sixiangkou chondrite. Earth Planet. Sci. Lett. 264, 277-283.

Chen, M., Sharp, T.G., El Goresy, A., Wopenka, B., Xie, X., 1996. The majorite-pyrope +magnesiowüstite assemblage: constraints on the history of shock veins in chondrites. Science 271, 1570-1573.

Chen, M., Li, H., El Goresy, A., Liu, J., Xie, X., 2006. Fracture-related intracrystalline transformation of olivine to ringwoodite in the Sixiangkou meteorite. Meteorit. Planet. Sci. 41, 731-737.

Christen, F., Eugster, O., Busemann, H., 2005. Mars ejection times and neutron capture effects of the nakhlites Y000593 and Y000749, the olivine-phyric shergottite Y980459, and the lherzolite NWA1950. Antarct. Meteorite Res. 18, 117-132.

Couvy, H., Frost, D.J., Heidelbach, F., Nyilas, K., Ungár, T., Mackwell, S., Cordier, P., 2004. Shear deformation experiments of forsterite at $11 \mathrm{GPA}-1400{ }^{\circ} \mathrm{C}$ in the multianvil apparatus. Eur. J. Mineral. 16, 877-889.

Eugster, O., Busemann, H., Lorenzetti, S., Terriblini, D., 2002. Ejection ages from krypton-81-krypton-83 dating and pre-atmospheric sizes of Martian meteorites. Meteorit. Planet. Sci. 37, 1345-1360.

Farber, D.L., Williams, Q., Ryerson, F.J., 1994. Diffusion in $\mathrm{Mg}_{2} \mathrm{SiO}_{4}$ polymorphs and chemical heterogeneity in the mantle transition zone. Nature 371, 693-695.

Farber, D.L., Williams, Q., Ryerson, F.J., 2000. Divalent cationen diffusion in $\mathrm{Mg}_{2} \mathrm{SiO}_{4}$ spinel (ringwoodite), $\beta$ phase (wadsleyite), and olivine. Implications for the electrical conductivity of the mantle. J. Geophys. Res. 105 (1), 513-529.

Folco, L., Franchi, I.A., 2000. Dar al Gani 670 shergottite: a new fragment of the Dar al Gani 476/489 Martian meteorite. Meteorit. Planet. Sci. 34 (Suppl.), A54-A55.

Folco, L., Franchi, I.A., D'Orazio, M., Rocchi, S., Schultz, L., 2000. A new Martian meteorite from the Sahara: the shergottite Dar al Gani 489. Meteorit. Planet. Sci. 35, 827-839.

Fritz, J., Greshake, A., 2009. High-pressure phases in an ultramafic rock from Mars. Earth Planet. Sci. Lett. 288, 619-623.

Fritz, J., Artemieva, N., Greshake, A., 2005. Ejection of Martian meteorites. Meteorit. Planet. Sci. 40, 1393-1411.

Fritz, J., Greshake, A., Stöffler, D., 2007. The Martian meteorite paradox: climatic influence on impact ejection from Mars? Earth Planet. Sci. Lett. 256, 55-60.

Frohlich, C., 1994. Earthquakes with non-double-couple mechanisms. Science 264, 804-809.

Ganguly, J., 2002. Diffusion kinetics in minerals: principles and applications to tectono-metamorphic processes. EMU Notes in Mineralogy 4; , pp. 271-309. (Chapter 10).

Gladman, B., 1997. Destination: Earth. Martian Meteorite Delivery. Icarus 130, $228-246$.

Green II, H.W., 2007. Shearing instabilities accompanying high-pressure phase transformations and the mechanics of deep earthquakes. Proc. Natl. Acad. Sci. 104, 9133-9138.

Greshake, A., Stöffler, D., 1999. Shock metamorphic features in the SNC meteorite Dar al Gani 476. Lunar Planet. Sci. XXX Houston, Texas, \#1377.

Greshake, A., Fritz, J., Böttger, U., 2011. Ringwoodite in the Martian Shergottite Dar al Gani 670: The Role of Shearing. In: Proceedings of the 42nd Lunar and Planetary Science Conference, March 7-11, 2011, The Woodlands, Texas. LPI Contribution no. 1608, p.1092.

Head, J.N., Melosh, H.J., Ivanov, B.A., 2002. Martian meteorite launch: high-speed ejecta from small craters. Science 298, 1752-1756.

Holzapfel, C., Chakraborty, S., Rubie, D.C., Frost, D.J., 2009. Fe-Mg interdiffusion in wadsleyite: the role of pressure, temperature and composition and the magnitude of jump in diffusion rate at the $410 \mathrm{~km}$ discontinuity. Phys. Earth Planet. Inter. 172, 28-33.

Jarosewich, E., Nelen, J.A., Norberg, J.A., 1980. Reference samples for electron microprobe analysis. Geostand Newsletters 4, 43-47.

Kerschhofer, L., Sharp, T.G., Rubie, D.C., 1996. Intracrystalline transformation of olivine to wadsleyite and ringwoodite under subduction zone conditions. Science 274, 79-81.

Kuebler, K.K., Jolliff, B.L., Wang, A., Haskin, L.A., 2006. Extracting olivine (Fo-Fa) compositions from Raman spectral peak positions. Geochim. Cosmochim. Acta 70, 6201-6222.

Kimura, M., Chen, M., Yoshida, Y., El Goresy, A., Ohtani, E., 2003. Backtransformation of high-pressure phases in a shock melt vein of an $\mathrm{H}$ chondrite during atmospheric passage: implications for the survival of highpressure phases after decompression. Earth Planet. Sci. Lett. 217, 141-150.

McMillan, P., Akaogi, M., 1987. Raman spectra of $\beta-\mathrm{Mg}_{2} \mathrm{SiO}_{4}$ (modified spinel) and $\gamma-$ $\mathrm{Mg}_{2} \mathrm{SiO}_{4}$ (spinel). Am. Mineral. 72, 361-364. 
Mainprice, D., Tommasi, A., Couvy, H., Cordier, P., Frost, D.J., 2005. Pressure sensitivity of olivine slip systems and seismic anisotropy of Earth's upper mantle. Nature 433, 731-733.

Meyer, C., 2013. Mars Meteorite Compendium. 〈http://curator.jsc.nasa.gov/antmet/ $\mathrm{mmc} /\rangle$.

Mikouchi, T., Miyamoto, M., McKay, G.A., 2001. Mineralogy and petrology of the Dar al Gani 476 Martian meteorite: implications for its cooling history and relationship to other shergottites. Meteorit. Planet. Sci. 36, 531-548.

Ming, L.C., Kim, Y.H., Manghnani, M.H., Usha-Devi, S., Ito, E., Xie, H.-S., 1991. Back transformation and oxidation of $(\mathrm{Mg}, \mathrm{Fe})_{2} \mathrm{SiO}_{4}$ spinels at high temperatures. Phys. Chem. Miner. 18, 171-179.

Miyahara, M., Ohtani, E., Kimura, M., El Goresy, A., Ozawa, S., Nagase, T., Nishijama, M., Hiraga, K., 2010. Coherent and subsequent incoherent ringwoodite growth in olivine of shocked L6 chondrites. Earth Planet. Sci. Lett. 295, 321-327.

Miyahara, M., El Goresy, A., Ohtani, E., Nagase, T., Nishijama, M., Vashaei, Z., Ferroir, T., Gillet, P., Dubrovinsly, L., Simionovivi, A., 2008. Evidence for fractional crystallization of wadsleyite and ringwoodite from olivine melts in chondrules entrained in shock-melt veins. Proc. Natl. Acad. Sci. 105, 8542-8547.

Miyahara, M., Ohtani, E., Ozawa, S., Kimura, M., El Goresy, A., Sakai, T., Nagase, T., Hiraga, K., Hirao, N., Ohishi, Y., 2011. Natural dissociation of olivine to (Mg,Si) $\mathrm{SiO}_{3}$ perovskite and magnesiowüstite in a shocked Martian meteorite. Proc. Natl. Acad. Sci. 108, 5999-6003.

Nishiizumi, K., Caffee, M.W., Irving, A.J., 2012. Exposure history of Tissint: evidence for 1.1 million year launch pairing with other depleted olivine-phyric shergottites. In: Proceedings of the 75th Annual Meteoritical Society Meeting Cairns, Australia, Abstract \#5349.

Ohtani, E., Kimura, Y., Kimura, M., Takata, T., Kondo, T., Kubo, T., 2004. Formation of high-pressure minerals in shocked L6 chondrite Yamato 791384: constraints on shock conditions and parent body size. Earth Planet. Sci. Lett. 227, 505-515.
Ohtani, E., Ozawa, S., Miyahara, M., Ito, Y., Mikouchi, T., Kimura, M., Arai, T., Sato, K. Hiraga, K., 2011. Coesite and stishovite in a shocked lunar meteorite, Asuka881757, and impact events in lunar surface. Proc. Natl. Acad. Sci. 108, 463-466.

Sharp, T.G., DeCarli, P.S., 2006. Shock effects in meteorites. In: Lauretta, D.S. McSween Jr., H.Y. (Eds.), Meteorites and the Early Solar System II. University of Arizona Press, Tucson, pp. 653-677.

Spray, J.G., 1995. Pseudotachylite controversy: fact or friction. Geology 23, 1119-1122.

Tschauner, O., Asimow, P.D., Kostandova, N., Ahrens, T.J., Ma, C., Sinogeiki, S., Liu, Z., Fakra, S., Tamura, N., 2009. Ultrafast growth of wadsleyite in shock-produced melts and its implications for early solar system impact processes. Proc. Natl. Acad. Sci. 106, 13691-13695.

Walton, E. 2013. Shock metamorphism of Elephant Moraine A79001: Implications for olivine-ringwoodite transformation and the complex thermal history of heavily shocked Martian meteorites. Geochim. Cosmochim. Acta 107, 299-315.

Wang, Y., Martinez, I., Guyot, F., Liebermann, R.C., 1997. The breakdown of olivine to perovskite and magnesiowüstite. Science 275, 510-513.

Weisberg, M.K., Kimura, M., 2010. Petrology and Raman spectroscopy of high pressure phases in the Gujba $\mathrm{CB}$ chondrite and the shock history of the $\mathrm{CB}$ parent body. Meteorit. Planet. Sci. 45, 873-884.

Xie, Z., Sharp, T.G., DeCarli, P.S., 2006. High-pressure phases in a shock-induced melt vein of the Tenham L6 chondrite: constraints on shock pressure and duration. Geochim. Cosmochim. Acta 70, 504-515.

Xie, Z., Sharp, T.G., 2007. Host rock solid-state transformation in a shock-induced melt vein of Tenham L6 chondrite. Earth Planet. Sci. Lett. 254, 433-445.

Zhang, A.C., Hsu, W.B., Floss, C., Li, X.H., Li, Q.L., Liu, Y., Taylor, L.A., 2010 Petrogenesis of lunar meteorite Northwest Africa 2977: constraints from in situ microprobe results. Meteorit. Planet. Sci. 45, 1929-1947.

Zipfel, J., Scherer, P., Spettel, B., Dreibus, G., Schultz, L., 2000. Petrology and chemistry of the new shergottite Dar al Gani 476. Meteorit. Planet. Sci. 35, 95-106. 